\title{
Indexação da RBR
}

Em todo grande empreendimento não é suficiente a um homem depender apenas de si.

\section{Isna Ia-wica}

(final do século XIX) Teton Sioux

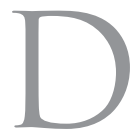
esde a sua fundação em 1947, durante a gestão de Waldemar Bianchi, tendo como secretário geral Hilton Seda e com a ajuda de Ayrthon Ferreira da Costa, a RBR estabeleceu como proposta de trabalho divulgar a produção científica dos reumatologistas brasileiros. Sempre considerando a qualidade de suas publicações a RBR atravessou períodos de maiores e menores dificuldades, recebendo um grande impulso renovador e consolidando-se como publicação em 1974 com o trabalho extraordinário do Professor Edgar Atra.

Nesta época, a SBR e as publicações científicas brasileiras na área de Reumatologia estavam conquistando seus primeiros degraus. Embora fosse evidente para todos o crescimento tanto da SBR quanto o da qualidade da ciência brasileira em Reumatologia, uma busca efetiva pela indexação no MEDLINE foi iniciada apenas em 1996 com Luis Eduardo Coelho de Andrade, editor científico da RBR. Esta iniciativa foi continuada pelos editores subsequentes: Natalino Yoshinari (19982000); Ieda Laurindo (2000-2002 e 2002-2004) com a criação do cargo de coeditor para os Professores Eloisa Bonfá, João Carlos Brenol e Hilton Seda, e com a indexação no SciELO; Lais Lage e Roger Levy (2004-2006) com a consolidação da indexação no SciELO e nova submissão ao MEDLINE; e Francisco Airton e Ricardo Xavier (2006-2008). Finalmente, recebendo da gestão Newbarth uma SBR estruturada e a caminho da profissionalização, foi possível à diretoria da SBR e aos editores Mittermayer Santiago e Ricardo Fuller elaborar uma estratégia para conseguir a tão almejada indexação.

Essa proposta foi apresentada a toda a diretoria da SBR, recebendo apoio incondicional dos presentes, que, diante da maturidade da reumatologia brasileira refletida pela SBR como sociedade e pela qualidade da nossa produção científica, julgaram que o momento seria adequado para uma nova tentativa. Todos estavam cientes de que essa nova tentativa seria realizada com o apoio e a orientação de uma editora internacional (Elsevier), implicando um tremendo esforço tanto em termos econômicos (aumento de custo previsto em mais de $60 \%$ ) quanto de trabalho, envolvendo inúmeros detalhes que incluíam a tradução de todos os artigos que passaram a ser publicados em inglês e português, a análise e a aprovação dos manuscritos dentro de um período de tempo restrito, os compromissos com a pontualidade da publicação, e o total comprometimento dos editores científicos e de todos os membros do conselho editorial da RBR com quem essa conquista deve ser compartilhada. É impossível não agradecer a todos esses colegas a confiança, o apoio e o trabalho.

Entretanto, o comprometimento de uma diretoria e/ou de editores científicos, contando ou não com o apoio manifesto dos colegas de diretoria e do conselho editorial jamais seria o bastante. Precisávamos da comunidade científica. Era essencial que as universidades e os pesquisadores confiassem na RBR, no esforço desenvolvido, e enviassem seus trabalhos, apesar das consequências relacionadas a uma piora na avaliação dos cursos de pós-graduação e na menor exposição dos trabalhos junto à comunidade científica internacional. Hoje esses cursos e esses 464 pesquisadores recebem nosso agradecimento, nosso reconhecimento e, tenho certeza, conosco celebram esta vitória.

É necessário também dividir esta conquista com os associados, agradecer a todos aqueles que, durante uma conversa, 
um comentário casual sobre a melhora da revista, sobre sua qualidade, deram a todos os envolvidos neste longo e exaustivo processo o ânimo para ultrapassar mais um pequeno/ grande detalhe.

A indexação da RBR é mais um exemplo de que nenhum empreendimento pode ser bem-sucedido se depender apenas de uma pessoa ou de um grupo por mais bem intencionados e dedicados que sejam! É o resultado de um processo que se desenvolveu ao longo de décadas, do esforço de cada um e de todos juntos.

Este é um editorial de "fim de ano" e, portanto, envolve um momento de reflexão e também de celebração. Mais um ano, mais um objetivo alcançado! Agradecimentos e celebrações!
É também um tempo de promessas, de estabelecer metas e de consolidar conquistas. Encerramos este editorial voltando à sequência de editores científicos da RBR e com a certeza de suas conquistas: Mittermayer Santiago e Ricardo Fuller (2008-2010 - indexação no MEDLINE), Max Victor Carioca Freitas e Paulo Louzada Junior (2010-2012 - consolidação da indexação e busca pelo índice de impacto), e aos futuros editores (2012-2014 - índice de impacto de 1,5, 2,8, ou talvez $4,2 \ldots)$ Vamos continuar trabalhando para obtermos um crescendo de comemorações!

Iêda M. M. Laurindo 